\title{
OS ESTUDOS SOBRE ONGS NAS PRODUÇÕES ACADÊMICAS EM POLÍTICAS EDUCACIONAIS: VISÕES E IMPLICAÇÕES
}

\author{
Grazielle Miranda Silva ${ }^{1}$ e Antonia Almeida Silva ${ }^{2}$ \\ 1. Bolsista PIBIC/CNPq, Graduando em Pedagogia, Universidade Estadual de Feira de Santana, e-mail: \\ grazimiranda3@gmail.com \\ 2. Orientador, Departamento de Educação - PPGE - Mestrado em Educação, Universidade Estadual de Feira de Santana, e- \\ mail: antoniasilv@gmail.com
}

PALAVRAS-CHAVE: Estado; ONG e Políticas Públicas.

\section{INTRODUÇÃO}

O presente trabalho, tem como objetivo identificar e analisar as visões e interpretações reveladas em teses e dissertações sobre as Organizações não Governamentais (ONGs), bem como sobre suas influências nas políticas educacionais. A pesquisa teve como pergunta norteadora: Quais as visões e interpretações sobre as ONGs e suas influências nas políticas educacionais se revelam em teses e dissertações produzidas nos programas de pós-graduação em educação que tiveram conceito igual ou superior a cinco na avaliação trienal da Coordenação de Aperfeiçoamento de Pessoal (CAPES), concluída em 2010?

A vista disso, apresento os seguintes objetivos específicos: Identificar os estudos que tratam do tema ONGs no banco de dados da pesquisa; Analisar as implicações destes trabalhos (teses e dissertações) na construção do campo de estudo em políticas públicas educacionais no Brasil e Apreender as concepções e visões apresentadas nos estudos sobre a atuação das ONGs na educação.

No esforço de compreender as conjunturas sociais vigentes, bem como interpretar o problema em questão, o estudo foi referenciado na abordagem histórico-crítica, tendo como conceitos analíticos o Terceiro setor e a relação público-privado. Esses conceitos permitiram o estudo do objeto explorando as relações entre os aspectos contextuais gerais e suas implicações no ordenamento das políticas educacionais, notadamente os movimentos de mudança no papel do Estado, conduzidos pelo desenvolvimento de argumentos e práticas que dão centralidade à atuação das ONGs na oferta de serviços até então exclusivos do setor público. Desse movimento depreendemos que a tensão da relação público-privado é estruturante para a análise do tema, o que justifica a escolha dos mesmos para estudo.

A atuação do terceiro setor na sociedade atual se constituiu/constitui em um projeto de organização social que dialoga com as ideias dominantes de superação da Crise do Capitalismo, por meio da parceria público - privado, fortalecendo ideais neoliberais, bem como, a lógica mercadológica.

\section{METODOLOGIA}

O presente estudo está em sintonia com uma pesquisa interinstitucional, denominada "Questões epistemológicas e metodológicas da produção acadêmica em políticas educacionais no Brasil (2000-2010)", por meio da qual foi realizado um amplo levantamento sobre a produção de teses e dissertações relacionadas com o campo das politicas públicas educacionais, em Programas de Pós-graduações em Educação com conceito igual ou superior a cinco na avaliação trienal da Coordenação de Aperfeiçoamento de Pessoal de Nível Superior (CAPES), concluída em 2010. Esse levantamento resultou em um banco de dados com 1.283 trabalhos coletados no Banco de Teses dessa mesma instituição, disponível para acesso público no site do grupo de pesquisas que abrigou esta pesquisa na UEFS (Centro de Estudos e de Documentação em Educação - CEDE - http://www2.uefs.br/cede/apresentacao-bd.html), assim como em publicações que analisaram os dados coletados, a exemplo do livro Pesquisa em políticas educacionais: características e tendências (SILVA; JACOMINI, 2016) . 
Inserida neste contexto, a presente pesquisa realizou um recorte desse banco de dados, focalizando as produções que tematizaram as ONGS. Foram identificadas 20 produções com essa temática.

A pesquisa foi inspirada na realização de sínteses sistemáticas de revisão de pesquisa, aproximando-se dos estudos do tipo estado da arte. Estas, conforme Ferreira (2002), caracterizam-se por pesquisas bibliográficas voltadas ao mapeamento de produções acadêmicas, objetivando vasculhar seus diferentes enfoques e prioridades, bem como levantar o debate sobre as tendências das produções e suas caraterísticas.

Utilizo como instrumento de pesquisa a catalogação das produções por meio dos descritores e dos resumos relacionados ao tema, a saber: ONGs e educação; Terceiro Setor e Educação.

\section{ANÁLISE E DISCUSSÃO DOS RESULTADOS}

O primeiro ponto de discussão desta pesquisa é a trajetória histórica e a conceituação do terceiro setor na sociedade brasileira, ainda que seu exercício seja carregado de armadilhas. Como estabelece Lélis $(2007$, p. 2009) conceituar o terceiro setor "é uma tarefa que impõe muitos desafios, tanto pela força ideológica que o mesmo evoca, quanto pela variedade de entidades que vem se organizando" em torno dos seus ideários. Na medida em que este setor foi-se expandindo e admitindo novas roupagens em suas visões políticas, observam-se mudanças na sua designação, desde a adulteração do conceito de cidadania, que passa a ser identificado com o de filantropia, o que acabou por gerar contradições internas para frações dos movimentos sociais historicamente identificados com as lutas pela garantia de direitos.

Nesse movimento, a atuação do terceiro setor, para alguns segmentos da sociedade, vem caracterizando-se como aquilo que não é nem mercado (privado) e nem Estado (público), mas como o público não estatal, conforme defende Bresser Pereira (1998). Esta visão, O terceiro setor, situa-se nesse entendimento como organizações com autonomia em prol do desenvolvimento profícuo da sociedade, vez que, supostamente, se distancia da lógica desigual do mercado, bem como da falência e ineficiência do Estado.

No entanto, é preciso perceber que, em meio as suas promessas e argumentos, envolvendo as afirmações de que o terceiro setor seria a alternativa para o reforço da "sociedade civil", assim como, para a efetivação da democracia e da cidadania, há um espaço de disputa de interesses e de poder que secundariza as pautas levantadas pela sociedade, bem como, impossibilita a efetivação da democracia e da cidadania, uma vez que não abre oportunidades para participação ativa da sociedade.

Em relação às produções acadêmicas selecionadas constatou-se que, no universo de 20 teses e dissertações identificadas, há uma dispersão grande entre as instituições que desenvolveram estudos com a temática ONGs/Terceiro setor e educação, conforme se vê no Gráfico 1:

\section{Gráfico 1}

Quantitativo de dissertações e teses, organizadas pela natureza, e suas instiuições (2000-2010)

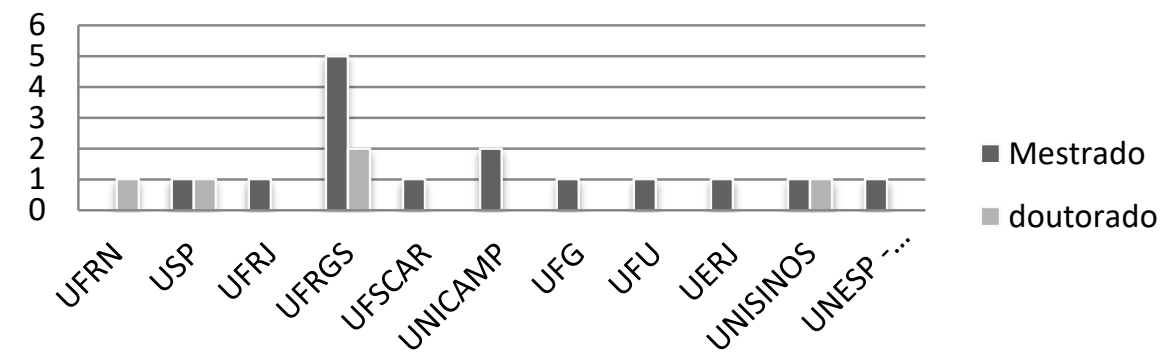




\section{Fonte: Elaboração própria com base em Silva (2014)}

Nota-se que o número de dissertações produzidas (15) é superior ao número de teses (cinco) encontradas. Segundo Macedo e Souza (2010, apud SILVA; JACOMINI, 2016) essa quantidade maior de dissertações pode ser explicada pela existência de um maior número de programas e de discentes de mestrado do quê de doutorado no Brasil. Percebemos ainda que a Universidade Federal do Rio Grande do Sul (UFRGS) é a instituição que mais produziu durante o período da pesquisa com cinco dissertações e duas teses, seguida da Universidade Estadual de Campinas (UNICAMP) com duas dissertações.

Quanto às visões e interpretações sobre as ONGs e suas influências nas políticas educacionais, constatou-se que duas visões básicas vêm polarizando as produções acadêmicas.

O primeiro grupo, composto por cinco produções, engloba trabalhos com estudos mais alinhados e favoráveis a atuação das ONGs, compreendo-as como positivas no desenvolvimento de funções voltadas a educação. O segundo grupo, composto por 15 produções, contém características opostas ao primeiro, sendo assim, abrange produções contrárias à atuação das ONGs.

Uma das características principais de diferenciação das produções dos dois grupos é a concepção de Estado e de suas funções. No primeiro grupo, por exemplo, os trabalhos encontrados alegam a morosidade do Estado em realizar suas funções e por isso apresentam as ONGs como forma de atender às lacunas deixadas por ele. No segundo percebe-se que há uma denúncia marcante das mudanças políticas trazidas pela globalização e pelo neoliberalismo, procurando evidenciar como elas são constitutivas da agenda de desestatização e, portanto, de fortalecimento do mercado e do próprio capital. À vista disso, nas produções deste grupo, são utilizados argumentos mais críticos em relação à atuação das ONGs. São trabalhos que se contrapõem ao modo como essas entidades do terceiro setor têm desempenhado suas funções, sobretudo por serem identificadas como instituições que fortalecem a hegemonia neoliberal e, por isso, contribuem para que o Estado se mantenha em confortável isenção do seu papel.

Do conjunto das 20 produções, foram selecionados para a leitura e análise integral seis trabalhos, sendo três do primeiro grupo (favoráveis a atuação das ONGs) e três do segundo (contrárias à atuação das ONGs), considerando suas a concepções de Estado e de suas funções em relação às políticas sociais?

No que se refere a visão sobre a influencia das ONGs nas políticas públicas educacionais, percebemos que elas são distintas. A primeira, representada pelos trabalhos do grupo 1, tem sido o canal para a difusão da noção de que "uma transformação necessária da educação nacional precisa juntar, antes de mais nada, as forças que até agora lutaram por uma educação para todos, democrática e de boa qualidade, situem-se elas no ensino público ou não." (CAMBA, 2004, p. 111). Sendo assim, a atuação das ONGs é vista como uma solução, para as melhorias do atendimento das políticas públicas.

A segunda visão, que representa o grupo 2, defende que a democratização se tornou um elemento chave nos discursos dos defensores do terceiro setor e das políticas neoliberais. De acordo com essa visão, a partir dos anos de 1990, as políticas educacionais foram marcadas por uma série de reformas, visando o ajuste das escolas às demandas do mercado de trabalho.

\section{CONSIDERAÇÕES FINAIS}

O estudo revelou que, a despeito da ampla difusão das ideias que situam o terceiro setor como alternativa para dar funcionalidade e governança ao setor público, na produção acadêmica sobre o tema ONG/terceiro setor, nos programas de pós-graduação selecionados, 
há um movimento consistente de contraposição a essa interpretação, visando a garantia dos direitos sociais e a defesa do Estado e do setor público como responsáveis diretos pela oferta de direitos tais como o da educação.

Diante do desenvolvimento desta pesquisa, compreende-se a sua contribuição para a construção do conhecimento sobre esta temática, tendo em vista que, os resultados exploram as formas como a mesma tem sido compreendida no meio acadêmico, demonstrando a complexidade do tema, bem como a heterogeneidade das visões sobre ele. Além disso, notase que a discussão sobre tema possui relevância social, principalmente diante das conjunturas sociais as quais estamos inseridos.

\section{REFERÊNCIAS}

CAMBA, S. V.. ONGs e escolas públicas: uma relação em construção. Dissertação (Mestrado) - Faculdade de Educação, Universidade de São Paulo, São Paulo, 2004. Disponível em: http://flacso.org.br/files/2017/07/Salete-disserta\%C3\%A7\%C3\%A3o-TotalGadotti-28-02-04-defesa.pdf

FERREIRA, Norma S. de A. As Pesquisas Denominadas "Estado Da Arte". Educação \& Sociedade. Campinas. n. 79, p.257-272. Ago.2002.

LÉLIS, U. A. de. Políticas e práticas do Terceiro Setor na educação brasileira, no contexto de reconfiguração do estado. 2006. 37 f. Dissertação (Mestrado em Ciências Humanas) - Universidade Federal de Uberlândia, Uberlândia, 2006.

PEGORARO, Ludimar. O Terceiro Setor e a Educação Superior no Brasil: compromisso social das fundações em Santa Catarina, o caso Universidade do Contestado. - Porto Alegre: UFRGS, 2008. 358 f. Tese (Doutorado em Educação) - Universidade Federal do Rio Grande do Sul. Faculdade de Educação. Disponível em: http://www.lume.ufrgs.br/handle/10183/13279

PEREIRA, Luiz C. B. Reconstruindo um novo Estado na América Latina. Brasília: ENAP, 1998.

PERONI, V. M. V; OLIVEIRA, R. T. C.; FERNANDES, M. D. E. Estado e terceiro setor: as novas regulações entre o público e o privado na gestão da educação básica brasileira. Educação \& Sociedade. Campinas, vol. 30, n. 108, p. 761-778. Out. 2009. Disponível em: http://www.cedes.unicamp.br/.

SILVA, Antônia A. (Coord.) et al. Produção acadêmica em políticas educacionais na Brasil - 2000 - 2010: dados dos programas conceito 5 ou mais. [banco de dados] Pesquisa Financiada pelo CNPq/CAPES nº7/2011. Feira de Santana: Cede, 2014. Disponível em: http://www2.uefs.br/cede/estudos.html.

SILVA, A. A.; JACOMINI, M. A. (orgs). Pesquisa em políticas educacionais: características e tendências. Feira de Santana. UEFS Editora, 2016. 